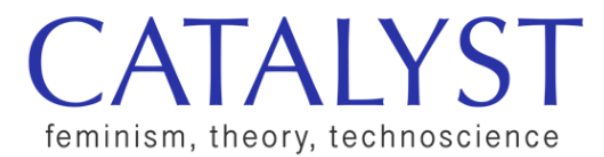

\title{
Postcolonial Assembly Protocols for Unnamed Automation Projects
}

\author{
Hemangini Gupta \\ Middlebury College \\ hgupta@middlebury.edu
}

\begin{abstract}
This creative contribution offers a sardonic manual to navigate the exuberant world of the startup economy in Bangalore, India, once known as a backend site of technological labor. As Bangalore fashions itself to become a "new" StartUp City, this manual continually tacks between the material sites and discourses of these seemingly new practices to bring into focus the persistent and revised forms of inequality that undergird them. Adopting the form of annotated keywords allows the manual to recast the circulating buzzwords of startup capitalism within their larger social and cultural histories. Each index entry expands a site of ethnographic investigation and cultural critique to allow the reader to explore the manual across registers: as a sardonic text, as a movement between words and their histories, and as an introduction to academic work that contextualizes technological experimentation.
\end{abstract}

Since the 1980 , the south Indian city of Bangalore has been developed by local state governments as a site for outsourced technology work. By the time I arrived in Bangalore to conduct ethnographic fieldwork between 2012 and 2014, entrepreneurs and technologists were uncoupling themselves from the tag of "outsourced labor" to fashion a new "Start Up City." State and private funding are channeled into the entrepreneurial economy, galvanized by the national government's emphasis on a "Make in India" policy. Bangalore is now imagined as an entrepreneurial ecosystem: a hub for technological innovation with 
entrepreneurial citizens.

Governments and private technology groups create flagship programs and funding streams such as "Start Up Karnataka" and the National Association of Software and Service Companies' (NASSCOM) "10000 startups," but individual technologists, too, do their part to differentiate this contemporary moment from the global labor chains of the past. In my interviews, technologists assured me that they weren't "cyber coolies," a term popularized by a cultural critic to signify the supposedly menial labor sent to back offices in India. Instead, they compare their innovations in machine learning with Gmail's predictive messaging.

Here in Bangalore, when entrepreneurs invent forms of automation-primarily robots-they are intended for business efficiency and cost-cutting (of course!), but also imagined as signifiers of value. Technologists travel widely to pitch to global markets and meet potential consumers, crafting themselves as cosmopolitan entrepreneurs. They are subjects emergent from colonial pasts that deemed them inferior, nationalist struggles that articulated science and technology as modernist projects, and neoliberal entrepreneurialism. Even as postcolonial entrepreneurs innovate, they galvanize caste identity, often reifying dominant Hindu and middle-class imaginations of a good life. I became interested in understanding this resolutely postcolonial form of innovation and its technoaffects, weaving so fluently between global signifiers of startup culture and the postcolonial ways in which entrepreneurs navigate this quixotic world.

This manual offers a startup kit to assemble a team, invent a robot, pitch to funders, and potentially disrupt an industry!

\section{Working Protocols}

1. Before assembly, please ensure you have ample Love. This is available on the bestseller shelf of the local Crosswords bookstore or at a streetside vendor. Labels differ depending on region. In parts of North America, Love may be sold under "Steve Jobs." Most Asian rising economies retail under the name of "It Happened in India" or "Never Give Up." If there has been a run on Love and it is not available at the time of assembly, then through creative and innovative experimentation, use a heartfelt combination of: Passion, Thirst, Inspiration, and Grit. If none of these are available, for Asian assembly, Love can be substituted by a combination of Parental Disowning, Social Stigma, and Inability to Secure an Arranged Marriage.

2. Confirm core team members before assembly. Ensure team members 
in Bangalore share your taste in craft beer and hanging out at local brewpubs.

3. For smooth operation of your new venture, ensure your core team members are educated at national technical institutes such as lyer lyengar Technology. Core members should live in gated communities on the city's outskirts. Their dispersal across the city will further the traffic snarls Bangalore is now known for; another separate manual (Technology for the Smart City.v1) is now available as an add on to this one.

4. Establish and popularize TikTok feeds, Instagram and Twitter accounts simultaneous to the assembly of your automation project. In case these websites are banned before you go to market, create a website. Images for the website can be culled from iStock photos to display casual Caucasian-skinned men chatting on bean bags. (Compare representational figures to the normate template and discard bodies that do not match the criteria in order to ensure the smooth flow of venture capital.)

5. Aside from startup founders, all employees should be project-based as "consultants." Precarious work environments create risk-taking appetite amongst disruptors in the ecosystem furthering chances of acquiring Series A funding from $Y$ Combinator. For clarification of all the terms just mentioned, please take an Uber auto to visit your closest WeWork.

6. Technologists who are working on the details of the actual invention need to demonstrate mastery over protocols related to East and West. They need proficiency in free software or open source coding, yoga teacher training credentials, should wear loose-fitting linen shorts. Ideally, they should have a favored spiritual guru or guiding philosopher, such as Swami Vivekananda, to similarly circulate successfully in the West as an Indian ambassador.

7. Technology experiments are typically tested on populations in the Global South. Since you are currently in the South, test your experimental automation on your own project team. If your automation can replace someone's labor, then you can successfully eliminate that job. Quickly disappearing teams may impact overall morale. Employees can be energized through group activities such as decorating the office during Diwali, designating every Friday as "sari day," and celebrating Ayudha Puja (see entry under Understanding Hinduism) with the distribution of free sweets. (Employees will assume their own responsibility for organizing and implementing 
these initiatives.)

8. If you are inventing a robot, we suggest a maximum of three syllables in a name gendered feminine. Proceed with bawdy tests. Organize test customers to demand sexual favors, ask personal questions, and share explicitly sexual content with the robot. The robot must accurately simper and divert the question. Please select a Colorado accent to proceed with racial branding. (If in doubt about what a Colorado accent is, please replace yourself with another startup founder.)

9. Correlate the level of surveillance programmed within the robot to its aesthetic appearance. Small amounts of surveillance should correspond directly with pleasing countenance. Robots that zealously record all conversations must simultaneously care for, calm, and control the environment in which they are deployed while appearing relatable, mysterious, and wholesomely sexy.

10. In small ways, your robot can enable a template for the future! Train fashion assistant robots to only activate when consumers are seated with knees close together, heads slightly tilted, mouths creased into a gentle welcoming smile. Cooking robots should default to assisting women's labor.

Congratulations! You just invented a postcolonial robot! When correctly executed, thoughtful initial programming can ensure a future in which all users are enabled to live longer, dress better, cook faster, and have guaranteed time to reproduce themselves!

\section{Index}

A

Ability (Techno-ableism)
How we envision the "proper" functioning of bodies and minds shapes our imaginations of the future and how we design its technological systems.

"Technoableism is a term I have coined to describe a rhetoric of disability that at once talks about empowering disabled people through technologies while at the same time reinforcing ableist tropes about what bodyminds are good to have and who counts as worthy." 
A. Shew. (2020). Ableism, technoableism, and future AI. IEEE Technology and Society Magazine, 39(1), 43. http://doi:10.1109/MTS.2020.2967492

B

\section{Building innovation}

C

\section{Caste}

D

Doing what you love
Innovation as key to India's development, offering a model for economic growth, social change, and a re-articulation of India's place in a global economy.

In India, innovation "was the promise that the nation's varied use values, sensibilities, and lifeways could be realized as improvement, as modernization, and as economic growth."

Irani, L. (2019). Chasing innovation: making entrepreneurial citizens in modern India. Princeton University Press. p. 15-16

Caste emerged through my fieldwork both as a form of privilege, enabling the elite education and material resources that allowed access to technical learning, and a system of naturalized preferences for the "life of the mind." As Renny Thomas shows in his ethnography of scientists at a premier institute in Bangalore, Brahmins' historical access to modern education and English education policy normalized their caste practices as scientific.

"Brahmin scientists' identity as casteless beings worked as a strategic tool to avoid questions of reservation and inclusion. Many scientists term their entry to science through 'passion,' 'merit' and 'interest.' Being Brahmins who had educated family members, it was not just passion, but also their cultural capital that helped them in doing science."

Thomas, R. (2020). Brahmins as scientists and science as Brahmins' calling: Caste in an Indian scientific research institute. Public Understanding of Science, 29(3), 313.

An ascendant global discourse that masks the conditions of labor and circulations of capital that enable so-called creative work. 
E

\section{Experiments}

$\mathbf{F}$

\section{Fashion}

G

Google
"But, ultimately, all of these romanticized motivations are masks, hiding the simple fact that work is work, even if it produces something cherished or beautiful."

Tokumitsu, M. (2015). Do what you love: And other lies about success and happiness. Regan Arts. p.2 .

Experiments as conjectural future-making assemblages, in Michelle Murphy's words.

"[I] define experiments in a broad sense as technical-social assemblies that arrange and gather data about interventions into the world toward the possibility of making something different happen."

Murphy, M. (2017). The economization of life. Duke University Press. p.og.

Echo Look's disciplining powers are internalized by subjects, and the technology extends disciplinary practices of sitting, smiling, and spatial movements.

"Echo Look emerges as the perfect tool for self-discipline through 360-degree views that render a view from nowhereanother example of unregulated gluttony of technological vision." (Parvin builds on Haraway, italics in original.)

Parvin, N. (2019). Look up and smile! Seeing through Alexa's algorithmic gaze. Catalyst: Feminism, Theory, Technoscience, 5(1), p. 4 https://doi.org/10.28g68/cftt.v5i1.29592

Innovators I spoke with in Bangalore were inspired by inventions like Gmail's predictive text in email.

"How do we ensure that our capacity is put to best use so we have not underutilized or overutilized people? Tech plays a big role in this. To me the best example of this innovation is Gmail and email. They have made it so much easier to send email." -Interview with a technologist in Bangalore, 5 September 2018 
$\mathrm{H}$

\section{Hanging out}

Christopher Kelty describes how he encounters the heavymetal, beer-drinking software culture in Bangalore's pubs. The reorientation of knowledge and power explored in Kelty's ethnography takes place not only through coding publics but through other avenues, such as tastes in music.

"Inside [the pub] it is dark and smoky, purple, filled with men between eighteen and thirty, and decorated with posters of Jimi Hendrix, Black Sabbath, Jim Morrison...All of the men, it appears, are singing along with the music, which is almost without exception heavy metal."

Kelty, C. M. (2008). Two bits: The cultural significance of free software. Duke University Press. p. 44.

(Today's techies might just as readily celebrate Ayudha Puja, in which prayers and offerings are placed before machines, signaling the diverse routes through which Hinduism comes to be "culturized" (see Thomas \& Geraci, 2018) thus redefining it as cultural practice.)

Thomas, R., \& Geraci, R. M. (2018). Religious rites and scientific communities: Ayudha Puja as "culture" at the Indian Institute of Science. Zygon, 1, 95. https://doi.org/10.1111/zygo.12380

lyer lyengar Technology or the Indian Institutes of Technology: key nodes in a process in which technological knowledge becomes disassociated with lower-caste artisans to become emblematic of upper-caste status (hence lyer, lyengar) and modernist projects of development.

"The majority of IITians come from upper-caste families of bureaucrats, school-teachers, and academics where capital has long been held in education. While most were already children of the professional class, the value of their accumulated capital has suddenly spiked due to the reorganization of late twentiethand early twenty-first-century capitalism around the 'knowledge economy.' At the same time, the role of caste and state in producing the IITian has been obscured in favor of his or her 
$J$

Jobs, Steve

K

Karnataka, Startup portrayal as a socially disembedded individual with an innate capacity for technical knowledge."

Subramanian, A. (2015). Making merit: The Indian institutes of technology and the social life of caste. Comparative Studies in Society and History, 57 (2), p. 293.

Stay hungry. Stay foolish.

"You have to trust in something-your gut, destiny, life, karma, whatever. This approach has never let me down, and it has made all the difference in my life."

Stanford. (2008, March 7). Steve Jobs' 2005 Stanford commencement address [Video]. YouTube. https://www.youtube.com/watch?v=UF8uR6Z6KLc

The state of Karnataka is channeling resources to build itself as a startup hub.

"The Government of Karnataka is proud to be the first state to announce the establishment of a dedicated Startup Cell! The Karnataka Startup Cell's aim is to promote Bangalore and Karnataka as the ultimate startup destination in the World." (cover page of Startup website, 15 July 2020)

Department of ITBT, KITS. (n.d.). Startup Karnataka. https://startup.karnataka.gov.in/

Vora and Atanasoski describe the global-racial erasures and disappearances undergirding techno-utopic fantasies of a postlabor society.

"By surrogate humanity, we mean to include not only specific technologies such as $3 \mathrm{D}$ printers and robots operating in factories that literally replace older spheres of human action and labor, but also the processes through which racialized, gendered, and sexualized spheres of life and labor are seemingly elided by technological surrogates, even as these spheres are 
replicated in emergent modes of work, violence, and economies of desire."

Atanasoski, N., \& Vora, K. (2015). Surrogate humanity:

Posthuman networks and the (racialized) obsolescence of labor. Catalyst: Feminism, Theory, Technoscience, 1(1), p. 3. https://doi.org/10.28g68/cftt.vi11.42

M

Mastery

$\mathbf{N}$

Normate

template

0

Open source coding
Entrepreneurs in Bangalore seek to find their footing as equals with their contemporaries in the West through a performance of their mastery over both spiritual and material domains of life.

"Across anticolonial discourse the mastery of the colonizer over the colonies was a practice that was explicitly disavowed, and yet, in their efforts to decolonize, anticolonial thinkers in turn advocated practices of mastery-corporeal, linguistic, and intellectual-toward their own liberation."

Singh, J. (2018) Unthinking mastery: Dehumanism and decolonial entanglements. Duke University Press. p. 2.

The normate template is the unmarked privilege of majority embodiments-white, male, cisgender, heterosexual, ablebodied, and middle-class bodies-that appear neutral when their social location is in fact highly specific.

"This 'mythic average norm' is not a neutral body but rather a particular white, European, nondisabled, youthful and often masculine figure whose features remain unmarked."

Hamraie, A. (2017). Normate template: Knowing-making the architectural inhabitant. In Building access: Universal design and the politics of disability. University of Minnesota Press. p. 20. https://doi.org/10.5749/j.ctt1pwt79d.5

Lilly Nguyen's interlocutor lives in a small town in the Mekong Delta but travels the world as an open source enthusiast.

"Through participation in the social worlds of these technologies, she met people from all over the world and these 
communities

$\mathbf{P}$

Pitching

Q

\section{Quixotic}

encounters fulfilled a deep-seated desire to overcome the dislocation of where she lived."

Nguyen, L. (2018). "This is not who we are": Freedom as moral affect and the whiteness of mutuality. Catalyst: Feminism, Theory, Technoscience, 4(1), p. 3. https://doi.org/10.28968/cftt.v4i1.29636

An entrepreneur explains how they arrived at their idea for a robot but then retrospectively framed it as an "aha" moment when pitching to investors who wanted a clear compelling narrative.

"When we were inventing [this cooking robot], R (founder)'s parents were both working, his mother would cook breakfast, lunch, dinner and the family changed three maids (as they weren't able to find someone satisfactory), then his mother decided that she would cook lunch, and the three siblings would cook dinner. As inventors, at that point we were winding down our wind turbine project and thinking of what to do next. R said, 'I hate to cook so let's build a machine that can cook, and all of it can be automated.' Of course, our investor story is that we always knew we wanted to do this but actually we had to brainstorm and find something to invent." Interview with startup founder in Bangalore, 6 December 2017

Startup entrepreneurs are expected to produce themselves as quixotic, unpredictable mavericks, in distinction to others who turn to business as a caste-related occupation.

"The will to automate emerges amidst multiple force fields: state ideologies, funding infrastructures and cycles, global entrepreneurial discourses and a postcolonial drive to situate Bangalore at the center rather than the periphery of innovation. Entrepreneurial companies with whom I conducted fieldwork were imagining themselves designing products and services for global markets. I recognize this shift to innovation and the emergence of the figure of the emboldened global entrepreneur as a unique moment of postcolonial experimentation." 
Gupta, H. (2019). Testing the future: Gender and technocapitalism in start-up India. Feminist Review, 123(1), 74.

$\mathbf{R}$

Racial branding

S

Software, free

T

Techno-affects
The presentation of race as a neoliberal strategy that operates through dynamics of race and gender in global markets.

"The legitimate and visible white female body in this configuration is the white female body that occludes the fact that the actual laboring body is a non-white body in the global South."

Guevarra, A. R. (2015). Techno-modeling care: Racial branding, dis/embodied labor, and "Cybraceros" in South Korea. Frontiers: A Journal of Women Studies, 36(3), p. 141. JSTOR. https://doi.org/10.5250/fronjwomestud.36.3.0139.

See also Phan, T. (2019). Amazon Echo and the aesthetics of whiteness. Catalyst: Feminism, Theory, Technoscience, 5(1), 1-38. https://doi.org/10.28g68/cftt.v5i1.29586

"I finished graduation and only wanted a job using open source software; at that time it was like men marrying men or something, it was unthinkable. My college had invited Stallman to speak to us (from the Free Software Foundation) and he made complete sense. At that time there was only Linux available. A teacher was also inspiring; he gave us use of a lab and guided us. This was in 1998. I was drawn to Linux because it made learning available to everybody without stealing or hacking."-Interview with a technologist in Bangalore, 5 September 2018

The environments in and through which technological formations create subjects, build horizons of possibility, and limit the imagination of a possible life.

"[A]n intense attachment that produces an alignment between a specific technological formation and a particular kind of subject." 
Amrute, S. (2019). Of techno-ethics and techno-affects. Feminist Review, 123(1), 56.

U

Understanding Hinduism

V

Value

W

WeWork, coworking space
How can we understand Indian discoveries and inventions in science and technology in the context of a right-wing Hindu nationalist government that lays claims to several scientific inventions as having originated in ancient India?

"Rather than characterize Hinduism as ancient, nonmodern, or traditional, the Hindu nationalists have embraced capitalism, Western science, and technology as elements of a modern, Hindu nation."

Subramaniam, B. (2019) Holy science: The biopolitics of Hindu nationalism. University of Washington Press. Location 266.

Indian scientists and technologists have long created their work as valuable in the context of colonial histories and nationalist struggles. Identities are created as forms of resistance.

"Nationalist ideology, which had a profound influence on women scientists of that era, tended to mask class, caste, and gender differences as it asserted a self-conscious and selfconfident Indian identity. Her insistence on downplaying gender in science can also be seen as a form of resistance to coercive identities imposed in the society at large, which limited women's potential. It did not entail a blanket denial of all difference but rather the denial of those formulations that posited different intellectual capabilities in men and women."

Sur, A. (2011). Dispersed radiance: Women scientists in C. V. Raman's laboratory. Meridians: Feminism, Race, Transnationalism, 1(2), p. 112.

The global co-working space now has several different branches in Bangalore.

A technologist I interviewed convinced his CEO to acquire space 
X

Xenophobia, addressed through robots

Y

Y Combinator

Z

Zealous recording here, as their regular office "has a different energy." He continued: "I don't know if you've noticed but there's a different kind of crowd here, it's more stylish, I have asked [my wife] to come and use this place too to meet clients [she's beginning a new career in image consulting]. The first time you meet someone it can be awkward but you just say hi, and then after that you say, oh hi, I've seen you here before!" - Interview with technologist in Bangalore, 5 September 2018

In Japan the declining birthrate, labor shortage, and rapidly aging population are treated as problems that need a "technological fix," and the government proposes Innovation 25 to promote a robot-dependent society that enables women to have more children with the help of robots. The added benefit is that robotic help eliminates the need for immigrant labor.

"[T]wentieth-century imperialism is being replaced with twentyfirst-century technological colonialism."

Robertson, J. (2018). Robo sapiens japanicus: Robots, gender, family, and the Japanese nation. California Scholarship Online.p. 57 https://doi.org/10.1525/california/9780520283190.001.0001

An accelerator lab that provides seed funding for startups.

About Y Combinator. (n.d.).

https://www.ycombinator.com/about/

The Indian government is increasing its surveillance through apps designed during COVID-19.

Pant, B., \& Lal, M. (2020, May 11). Aarogya Setu app: A tale of the complex challenges of a rights-based regime. The Wire. https://thewire.in/tech/aarogya-setu-app-challenges-rightsbased-regime 


\section{Acknowledgements}

Thanks to Nassim Parvin for her editorial vision and practice and to Moyukh Chatterjee who reads more first drafts than anyone should have to.

\section{Author Bio}

Hemangini Gupta is completing a manuscript that analyzes startup capitalism in Bangalore, India. She has a PhD in women's gender and sexuality studies from Emory University, and teaches classes on transnational feminisms, technological futures, and capital and labor at Middlebury College. 